\title{
Reoperative endoscopic endonasal surgery for residual or recurrent pituitary adenomas
}

\author{
Hazem M. Negm, MBChB, MSc, MD, ${ }^{1,4}$ Rafid Al-Mahfoudh, MBChB, FRCS(SN),1,5 \\ Manish Pai, MBBS, MS, MCh, ${ }^{1,6}$ Harminder Singh, MD, ${ }^{1,9}$ Salomon Cohen, MBBS, ${ }^{1,7}$ \\ Sivashanmugam Dhandapani, MBBS, MCh, ${ }^{1,8}$ Vijay K. Anand, MD, ${ }^{2}$ and \\ Theodore H. Schwartz, MD1-3
}

Departments of ${ }^{1}$ Neurological Surgery, ${ }^{2}$ Otolaryngology, and ${ }^{3}$ Neuroscience, Weill Cornell Medical College, NewYork-Presbyterian Hospital, New York, New York; " Department of Neurosurgery, Menoufia University, Menoufia, Egypt; ${ }^{5}$ South East Neurosurgery and Spinal Surgery, Brighton and Sussex University Hospitals NHS Trust, East Sussex, United Kingdom; ${ }^{6}$ Tata Main Hospital, Jamshedpur, India; 'Department of Neurosurgery, National Institute of Neurology and Neurosurgery, "Manuel Velasco Suarez," Mexico City, Mexico; ${ }^{8}$ Department of Neurosurgery, Post Graduate Institute of Medical Education and Research, Chandigarh, India; and ${ }^{9}$ Stanford University School of Medicine, Stanford, California

OBJECTIVE Regrowth of the lesion after surgical removal of pituitary adenomas is uncommon unless subtotal resection was originally achieved in the first surgery. Treatment for recurrent tumor can involve surgery or radiotherapy. Locations of residual tumor may vary based on the original approach. The authors evaluated the specific sites of residual or recurrent tumor after different transsphenoidal approaches and describe the surgical outcome of endoscopic endonasal transsphenoidal reoperation.

METHODS The authors analyzed a prospectively collected database of a consecutive series of patients who had undergone endoscopic endonasal surgeries for residual or recurrent pituitary adenomas after an original transsphenoidal microscopic or endoscopic surgery. The site of the recurrent tumor and outcome after reoperation were noted and correlated with the primary surgical approach. The chi-square or Fisher exact test was used to compare categorical variables, and the Mann-Whitney U-test was used to compare continuous variables between surgical groups.

RESULTS Forty-one patients underwent surgery for residual/recurrent pituitary adenoma from 2004 to 2015 at Weill Cornell Medical College. The previous treatment was a transsphenoidal microscopic $(n=22)$ and endoscopic endonasal $(n=19)$ surgery. In $83.3 \%$ patients $(n=30 / 36)$ there was postoperative residual tumor after the initial surgery. A residual tumor following endonasal endoscopic surgery was less common in the sphenoid sinus $(10.5 \%$; $2 / 19)$ than it was after microscopic transsphenoidal surgery $(72.7 \% ; n=16 / 22 ; p=0.004)$. Gross-total resection (GTR) was achieved in $58.5 \%$, and either GTR or near-total resection was achieved in $92.7 \%$. Across all cases, the average extent of resection was $93.7 \%$. The rate of GTR was lower in patients with Knosp-Steiner Grade 3-4 invasion $(p<0.0005)$. Postoperative CSF leak was seen in only one case $(2.4 \%)$, which stopped with lumbar drainage. Visual fields improved in $52.9 \%(n=9 / 17)$ of patients and were stable in $47 \%(n=8 / 17)$. Endocrine remission was achieved in $77.8 \%(n=14 / 18)$ of cases, 12 by surgery alone and 2 by adjuvant medical $(n=1)$ and radiation $(n=1)$ therapy. New diabetes insipidus occurred in $4.9 \%(n$ $=2 / 41$ ) of patients-in one of whom an additional single anterior hormonal axis was compromised-and $9.7 \%(n=4 / 41)$ of patients had a new anterior pituitary hormonal insufficiency.

CONCLUSIONS Endonasal endoscopic reoperation is extremely effective at removing recurrent or residual pituitary adenomas that remain after a prior surgery, and it may be preferable to radiation therapy particularly in symptomatic patients. Achievement of GTR is less common when lateral cavernous sinus invasion is present. The locations of residual/ recurrent tumor were more likely sphenoidal and parasellar following a prior microscopic transsphenoidal surgery and sellar following a prior endonasal endoscopic surgery.

https://thejns.org/doi/abs/10.3171/2016.8.JNS152709

KEY WORDS adenoma; craniotomy; endonasal endoscopic; pituitary tumor; reoperation; skull base; transsphenoidal; pituitary surgery

ABBREVIATIONS ACTH = adrenocorticotropic hormone; $\mathrm{DI}=$ diabetes insipidus; $\mathrm{EOR}=$ extent of resection; $\mathrm{FSH}=$ follicle-stimulating hormone; GH = growth hormone; GTR = gross-total resection; IGF-1 = insulin-like growth factor 1; LH = luteinizing hormone; PRL = prolactin; TSH = thyroid-stimulating hormone.

SUBMITTED November 29, 2015. ACCEPTED August 3, 2016.

INCLUDE WHEN CITING Published online October 28, 2016; DOI: 10.3171/2016.8.JNS152709. 
$\mathrm{P}$ TUITARY adenomas are the third most common intracranial neoplasm, accounting for $14.4 \%$ in autopsy studies and $22.5 \%$ in radiological studies, although only about $10 \%$ are symptomatic..$^{18,58}$

Despite their benign nature and infradiaphragmatic origin, they can extend outside the sella into the suprasellar, infrasellar, and/or cavernous sinus regions. They present with autonomous hormone secretion or, more commonly, as nonfunctioning tumors producing mass effect. Common presentations are headaches, visual changes if the lesion extends toward the optic chiasm, and ophthalmoplegia with lateral extension into the cavernous sinus. ${ }^{16,22,36,39,47}$

Resection continues to be the preferred initial treatment except in cases of prolactin (PRL)-secreting tumors..$^{11,28 \text {, }}$ 36,39,40,48,52,65 The outcomes following transsphenoidal pituitary surgery have been generally excellent, with high rates of clinical improvement, endocrinological remission, and minimal rates of morbidity and mortality. ${ }^{16,17,28,36,39,40,65}$ The use of the endoscope has recently transformed transsphenoidal surgery by providing a wider and better-illuminated field of view. $10,14,15,16,17,24,25,34$ For de novo adenoma presentation, endoscopy results in complete tumor removal in about $80 \%$ of cases, hormone resolution in $80 \%-85 \%$, and a low incidence of complications and death $(<2 \%$ CSF leak and $0.24 \%$ mortality rate).$^{62}$ Other potential advantages include reduced nasal trauma, no need for nasal packing, shorter, more comfortable postoperative hospital stay, and higher postoperative quality of life. ${ }^{45,62}$

Despite the surgical advantages of the endoscope, tumors can recur, although not commonly after complete resections. Recurrence rates for pituitary adenoma after complete resection are reported to be between $7 \%$ and $33 \% .{ }^{8}$ The rate varies depending on the type of adenoma: $10 \%$ risk for growth hormone $(\mathrm{GH})$-secreting tumors, $13 \%$ for adrenocorticotropic hormone (ACTH)-secreting tumors, $20 \%$ for prolactinomas, and $26 \%$ for nonsecreting adenomas. ${ }^{1,13}$ Regrowth after incomplete tumor removal occurs in up to $75 \%$ of cases. ${ }^{1,7,8,13}$ Of these, between $6 \%$ and $37.5 \%$ are symptomatic. ${ }^{38}$

Unlike primary surgery, revision surgery is usually more difficult due to septal and intrasellar scarring and anatomy that has been distorted by the previous dissection. Harvesting a nasoseptal flap is more challenging and the rate of invasive adenomas in the cavernous sinus and other parasellar areas is higher, since these factors led to incomplete resection in the first place. For these reasons, reoperative pituitary surgery has been reported to result in an overall lower cure rate and higher morbidity rate., ${ }^{7,32,41}$ Residual or recurrent tumors are often treated with nonsurgical therapies such as observation, medical therapy, radiotherapy, radiosurgery, all with low procedure-related morbidity. ${ }^{5,41}$ However, revision surgery is often required when a tumor is very large, close to the optic apparatus, or is hormone secreting. 9.48

Although a few articles have been published on reoperative transsphenoidal surgery, there has been little discussion of the success of the surgery and the tumor location based on the prior approach. Likewise, there are limited reports on the endoscopic approach for recurrent or residual pituitary adenomas. In this article, we analyze a series of endoscopically resected recurrent and residual pituitary adenomas previously operated on via a transsphenoidal approach, either microsurgical or endoscopic. Surgical results and complications are reported and compared with the existing literature.

\section{Methods}

We reviewed a prospectively collected database of all patients who underwent reoperative endoscopic endonasal transsphenoidal surgery, with extended approaches employed as needed, for recurrent pituitary adenoma at Weill Cornell Medical College, NewYork-Presbyterian Hospital between February 2004 and June 2015. All surgeries were performed by the senior authors (T.H.S. and V.K.A.). This series is part of Endoscopic Skull Base Surgery Institutional Review Board protocol approved by Weill Cornell Medical College. Appropriate patient consent was obtained.

Patients included in the study were divided into those who had prior microscope-based transsphenoidal surgery and those who had prior endonasal endoscopic surgery. Indications for surgery included prior subtotal resection with persistent mass effect on the chiasm, persistent hormone hypersecretion, and significant regrowth of a tumor not deemed a candidate for radiotherapy based on it proximity to the optic chiasm, the young age of the patient, or regrowth of tumor after prior radiation therapy.

Demographic data, prior treatments such as surgical interventions and/or medical and/or radiotherapy, duration of surgery, estimated blood loss, type of exposure, use of intraoperative fluorescein, lumbar drainage, closure technique, and complications were retrieved from our electronic database.

All patients underwent contrast-enhanced volumetric MRI before surgery and also 1-2 days postoperatively, 3 months postoperatively, and then at yearly intervals thereafter. Tumor volumes were assessed by the ellipsoid model " $(\mathrm{ABC}) / 2$ " equation. Cavernous sinus invasion was classified according to Knosp-Steiner criteria. ${ }^{33}$ The extent of resection (EOR) was evaluated on MRI studies obtained 3 months following surgery; extent was categorized, according to the amount of tumor removed, as 1) partial (< $50 \%$ volume removed), 2) subtotal (50\%-80\% volume removed), 3) near-total resection (80\%-99\% volume removed), and 4) gross-total (100\% volume removed) resection (GTR).

All cases were evaluated routinely by a neuroophthalmologist who assessed preoperative and postoperative visual fields.

\section{Endocrinological Evaluation}

All patients underwent pre- and postoperative endocrinological evaluation for free cortisol, $\mathrm{ACTH}$, free thyroxine, thyroid-stimulating hormone (TSH), PRL, GH, insulin-like growth factor 1 (IGF-1), testosterone, estradiol, luteinizing hormone (LH), and follicle-stimulating hormone (FSH) to assess for endocrinological derangements. ${ }^{1}$

The diagnosis of a prolactinoma was made based on serum PRL levels of $>150 \mathrm{ng} / \mathrm{ml}$ in combination with typical clinical symptoms. In patients with prolactinoma, endocrinological remission was defined as a postoperative 
PRL level of $<20 \mathrm{ng} / \mathrm{ml}$ in females or $<15 \mathrm{ng} / \mathrm{ml}$ in males without dopaminergic therapy for at least 2 months. ${ }^{9}$

The diagnosis of Cushing disease was based on either abnormal 24-hour urinary free cortisol or abnormal results on low-dose dexamethasone suppression tests, defined as failure of $1 \mathrm{mg}$ of dexamethasone to reduce plasma cortisol levels to $<1.8 \mathrm{mg} / \mathrm{ml}$ the next morning. In Cushing disease, endocrinological remission was defined as an early morning cortisol level measurement of $1.8 \mathrm{mg} / \mathrm{ml}$ obtained within 48 hours after surgery or a normalization of the 24hour urinary free cortisol. 3,50

The diagnosis of acromegaly was based on abnormal basal fasting levels of GH and IGF-1. Biochemical remission was defined as an IGF-1 value within normal range for age and sex and a $\mathrm{GH}$ value $<0.4 \mathrm{ng} / \mathrm{mL}$ after a $75-\mathrm{g}$ oral glucose load or a random $\mathrm{GH}$ value $<1.0 \mathrm{ng} / \mathrm{ml} .^{21}$

A basal cortisol level of $<5 \mathrm{ug} / \mathrm{dl}$ was also considered as evidence of central hypoadrenalism. Central hypothyroidism was defined as a free $\mathrm{T} 4<0.8 \mathrm{ng} / \mathrm{dl}$ with a subnormal TSH response. Serum testosterone was measured in male patients before surgery and at follow-up. Central hypogonadism was defined as a testosterone level $<200$ $\mathrm{ng} / \mathrm{dl}$ in males and amenorrhea in females with inappropriately low FSH and LH levels. ${ }^{11,36}$

Postoperatively, diabetes insipidus (DI) was diagnosed if 1) serum sodium was $>145 \mathrm{mmol} / \mathrm{L}$ or 2) the patient required desmopressin, and permanent DI required desmopressin administration for more than 3 months. ${ }^{49,53,60,61}$

\section{Surgical Technique}

The standard surgical techniques for pituitary adenoma have been previously described, and only the portions unique to our center or specifically related to the recurrent cases are detailed herein. ${ }^{1}$ Following induction of general anesthesia, antibiotics, $50 \mathrm{mg}$ of diphenhydramine, and $10 \mathrm{mg}$ of dexamethasone were given. A lumbar puncture was performed routinely, and $0.25 \mathrm{ml}$ of $10 \%$ fluorescein (Akorn Inc.) was injected in $10 \mathrm{ml}$ of CSF to help visualize CSF leaks. ${ }^{4,15,17,31,55,57}$ In cases involving tumors $>2.5$ $\mathrm{cm}$ in height with a $>1-\mathrm{cm}$ extension above the planum, a lumbar drain is placed for postoperative drainage (rate of $5 \mathrm{ml} /$ hour) for 1 day. The patient's head was placed in 3-point fixation, and intraoperative navigation was used in all cases. Micro-Doppler was used all cases. In cases involving a larger tumor $>2.5 \mathrm{~cm}$ in vertical height with a $>1-\mathrm{cm}$ extension above the planum, a nasoseptal flap was harvested, usually the side contralateral to a previous approach, and even a bilateral "Janus" flap was elevated in some cases. ${ }^{4,31,55,63}$ If a prior flap existed from the first surgery, the flap was taken down off the skull base and reused at the end of the operation.

We believe that the key to successful reoperation is a wide sphenoidotomy with drilling of all septations and a wide opening of the sella from the cavernous sinus to the cavernous sinus in the horizontal dimension and from the superior intercavernous sinus superiorly to the sellar floor inferiorly. It was not uncommon for the sphenoid and sella to have been inadequately opened in the first operation, which was the cause of the inadequate primary result. If the tumor extended into the cavernous sinus, then a transcavernous approach was used. ${ }^{16,20,44,56,67}$ If there was sig-
TABLE 1. Preoperative characteristics

\begin{tabular}{lc}
\hline \multicolumn{1}{c}{ Characteristic } & No. of Patients (\%) \\
\hline Mean age \pm SD (yrs) & $54 \pm 17$ \\
\hline Sex & $22(53.7)$ \\
\hline Male & $19(46.3)$ \\
\hline Female & 73 \\
\hline Mean time from previous op (mos) & $17(41.5)$ \\
\hline Clinical presentations & $11(26.8)$ \\
\hline Visual loss & $8(19.5)$ \\
\hline Bitemporal field cuts & $17(41.5)$ \\
\hline Headaches & $3(7.3)$ \\
\hline Endocrine hyperfunction & $13(31.7)$ \\
\hline Diplopia & $2(4.9)$ \\
\hline Progressive growth & \\
\hline Apoplexy & $9(22)$ \\
\hline Prior hormonal deficiency & $2(4.9)$ \\
\hline Overall & $2(4.9)$ \\
\hline DI & $5(12.2)$ \\
\hline Single axis
\end{tabular}

Values represent the mean (\%) number of patients unless otherwise stated.

nificant suprasellar extension, then the tuberculum sella was opened and an extracapsular removal of the suprasellar component was performed. . $^{15,17,37,42,59}$ Closure was performed according to our previously published algorithm. ${ }^{54}$

\section{Statistical Analysis}

Continuous variables are presented as the mean values \pm SD and range. Categorical values are shown as percentages. The chi-square or Fisher exact test was used to compare categorical variables, and the Mann-Whitney U-test was used to compare continuous variables between surgical groups. A p value $<0.05$ was considered significant.

\section{Results}

We identified 41 patients who underwent reoperation in which the endoscopic endonasal transsphenoidal approach was used for the treatment of recurrent pituitary adenomas (Table 1). They were grouped according to prior surgery into one of two groups: transsphenoidal microscopic (22 patients [53.7\%]) and endoscopic endonasal (19 patients [46.3\%]). The mean tumor volume for each of the groups was $9.1 \mathrm{~cm}^{3}$ and $4.6 \mathrm{~cm}^{3}$, respectively. Thirty-six patients $(87.8 \%)$ had undergone a single prior surgery, 4 (9.8\%) had 2 prior surgeries, and the remaining 2 patients (4.9\%) had 3 or more prior surgeries. The prior surgery was performed by the senior author (T.H.S.) in 4 cases, with the remainder referred from other institutions.

Seventeen (41.5\%) of 41 patients had visual symptoms. Preoperative visual field testing revealed bitemporal field cuts in 11 patients $(26.8 \%)$. Patients with impaired vision had significantly larger tumors compared with patients who sought medical attention for other symptoms $\left(13.96 \mathrm{~cm}^{3} \mathrm{vs}\right.$ $2 \mathrm{~cm}^{3}$, respectively; $\mathrm{p}<0.01$, Mann-Whitney U-test). Sev- 
TABLE 2. Preoperative characteristics of pituitary tumors residuals/recurrences classified by prior approaches

\begin{tabular}{|c|c|c|c|}
\hline \multirow[b]{2}{*}{ Characteristic } & \multirow[b]{2}{*}{ Total } & \multicolumn{2}{|c|}{ Group } \\
\hline & & $\operatorname{TSM}(n=22)$ & $\operatorname{EE}(n=19)$ \\
\hline Mean tumor vol $\left(\mathrm{cm}^{3}\right)$ & 7 & 9.1 & 4.6 \\
\hline \multicolumn{4}{|l|}{ Tumor location } \\
\hline Limited to sella & 13 & $5(22.7)$ & $8(42.1)$ \\
\hline Suprasellar & 18 & $12(54.5)$ & $6(31.6)$ \\
\hline Sphenoid sinus & 18 & $16(72.7)$ & $2(10.5)$ \\
\hline Cavernous sinus & 16 & $11(50)$ & $5(26.3)$ \\
\hline Clivus & 7 & $4(18.2)$ & $3(15.8)$ \\
\hline Mean time btwn initial \& reop (mos) & & 105 & 38 \\
\hline \multicolumn{4}{|l|}{ EOR after prior surgery } \\
\hline Incomplete prior excision & 30 & $17 / 19(89.5)$ & 13/17 (76.5) \\
\hline $\begin{array}{l}\text { Recurrence after complete prior } \\
\text { excision }\end{array}$ & 6 & $2 / 19(10.5)$ & $4 / 17(23.5)$ \\
\hline Unknown prior rate of excision & 5 & 3 & 2 \\
\hline
\end{tabular}

$\mathrm{EE}=$ endoscopic endonasal; TSM = transsphenoidal microscopic.

Values represent the mean (\%) number of patients unless otherwise stated.

enteen patients (41.5\%) had serological evidence of hormone overproduction. Hormone-producing tumors were significantly smaller than non-hormone-secreting ones (1 $\mathrm{cm}^{3}$ vs $11.75 \mathrm{~cm}^{3}$, respectively; $\mathrm{p}<0.01$, Mann-Whitney Utest). Prior surgery in cases of hormone-producing tumors was microscopic transsphenoidal in $8(36.4 \%)$ of 22 patients and endonasal endoscopic in $9(47.4 \%)$ of 19 patients. Nine patients included in the current series presented with preexisting hypothalamic-pituitary axis impairment (Table 1). Hormonal deficiencies included panhypopituitarism in 5 cases, hypogonadism in 1 case, and hypothyroidism in 1 case, as well as DI in 2 cases. Headaches were present in 8 patients $(19.5 \%)$.

The mean interval between the previous surgery and the reoperative endoscopic endonasal surgery was 73 months. This interval was significantly shorter in the endonasal endoscopic group than in the transsphenoidal microscopic group (38 months vs 105 months, respectively; $\mathrm{p}<0.01$, Mann-Whitney U-test). The interval from prior surgery to reoperation was significantly shorter in patients with hormone-producing than non-hormone-producing adenomas in the endoscopic group ( $\mathrm{p}<0.01)$.

\section{Tumor Recurrence}

Owing to the lack of adequate records from the prior surgery, it was not known if the prior resection was complete in 5 patients. Of the other 36 patients, a postoperative residual tumor was documented in $83.3 \%(\mathrm{n}=30)$ and a GTR in $16.7 \%(\mathrm{n}=6)$ of patients. Postoperative residual tumor was seen in $17(89.5 \%)$ of 19 patients who underwent transsphenoidal microscopic surgery and in 13 (76.5\%) of 17 patients who underwent endoscopic surgery (Table 2).

The endoscopic and microscopic groups were comparable in terms of the initial tumor locations. All tumors had an initial sellar component. Initial tumors in the endoscopic and microscopic groups were suprasellar $(n=14 / 18$ [78\%] and $n=16 / 22$ [73\%], respectively), in the cavernous

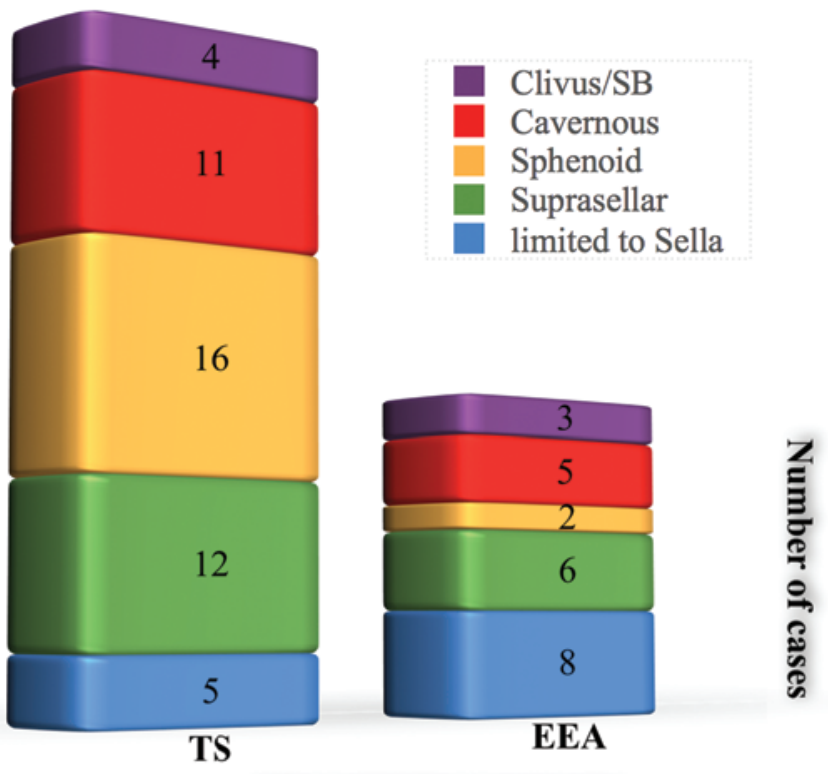

Type of prior approach

FIG. 1. Tumor recurrence in different regions after different prior approaches. EEA = endoscopic endonasal approach; SB = skull base; TS $=$ transsphenoidal microscopic approach. Figure is available in color online only.

sinus (6/18 [33\%] and 8/22 [36\%]), and invading the sphenoid sinus $1 / 18$ [6\%] and 4/22 [18\%]), respectively (Table 2 ). In both groups the initial tumor locations were comparable.

In the microscopic transsphenoidal group, the most common location of recurrent or residual tumor was in the sphenoid sinus $(72.7 \%)$ followed by the suprasellar cistern $(50 \%)$ and the cavernous sinus (50\%) (see Fig. 2). For the endonasal endoscopic group, the most common site of recurrence was sellar (42.1\%) (see Figs. 3A and 5). Regions of recurrent pituitary tumors in different groups are presented in Table 2. Statistical significance was achieved for the low rate of sphenoid sinus recurrence in patients who had previously undergone endonasal endoscopic surgery $(10.5 \%)$ compared with microscopic transsphenoidal surgery $(72.7 \% ; p=0.004)($ Fig. 1$)$. This difference was not statistically significant before the first surgery $(p=0.2)$. A prior microscopic transsphenoidal approach resulted in regrowth of tumor in the sphenoid sinus $(n=4 / 4)$, whereas a prior endoscopic endonasal approach succeeded in removal of the sphenoidal component $(n=1 / 1)$. Fourteen patients had a newly grown sphenoidal tumor, in 12 of whom the lesion had developed after microscopic transsphenoidal surgery versus 2 in whom it had developed after endoscopic endonasal surgery $(p=0.003)$ (Table 2). All the patients who had an initial sphenoidal component and who had initially undergone microscopic transsphenoidal surgery had regrowth of the sphenoid sinus residual mass $(n=4 / 4)$, whereas in the one patient who had initially undergone an endoscopic endonasal procedure, the success of the initial sphenoidal component excision persisted.

Both the size and rate of invasion of pituitary tumors were significantly higher in cases of nonfunctioning adenomas, but there was no such difference when examined 
TABLE 3. Pathology subtypes of pituitary adenomas

\begin{tabular}{|c|c|c|c|c|c|c|c|c|}
\hline \multirow[b]{2}{*}{ Characteristic } & \multicolumn{3}{|c|}{ Functioning $41 \%(n=17)$} & \multicolumn{4}{|c|}{ Nonfunctioning $59 \%(n=24)$} & \multirow{2}{*}{$\begin{array}{c}p \\
\text { Value }\end{array}$} \\
\hline & PRL & $\mathrm{GH}$ & ACTH & Null & $\mathrm{ACTH}$ & $\mathrm{FSH} / \mathrm{LH}$ & $\mathrm{GH}$ & \\
\hline No. of tumors & 4 & 9 & 4 & 9 & 2 & 12 & 1 & \\
\hline Average tumor vol $\left(\mathrm{cm}^{3}\right)$ & 1 & 1 & 3 & 6 & 6.2 & 15 & 6.4 & $<0.01$ \\
\hline Invasion & 3 & 4 & 2 & $9 / 10$ & 2 & 11 & 1 & 0.0035 \\
\hline Recurrence \& reop & 1 & - & 2 & - & - & 2 & 1 & NS \\
\hline EOR & $98 \%$ & $98 \%$ & $95 \%$ & $93 \%$ & 100 & 89 & $93 \%$ & NS \\
\hline GTR & $3 / 4$ & $7 / 9$ & $2 / 4$ & 5 & - & 7 & - & NS \\
\hline
\end{tabular}

NS = not significant.

by the pathological subgroups. The EOR, rate of GTR, and incidence of recurrence or regrowth that needed reoperation were comparable in functional and nonfunctional groups (Table 3).

Patients with Ki 67 expression greater than 5\% had significantly larger tumors and greater invasion of the surrounding structures, and they had multiple reoperations for repeated recurrence or regrowth. These cases had a tendency for lower extent of resection and GTR but no statistical significance could be proved (Table 4).

\section{Outcome}

The average postoperative follow-up duration was 39 months (range 3-135 months). Overall GTR was achieved in 24 cases $(58.5 \%)$, and either GTR or near-total resection was achieved in $92.7 \%$. The average preoperative volume in GTR cases was smaller than those in which GTR was not achieved $\left(3.7 \mathrm{~cm}^{3}\right.$ vs $11.7 \mathrm{~cm}^{3} ; \mathrm{p}<0.05$, Mann-Whitney U-test). The mean EOR for the entire group was $93.7 \%$. GTR did not differ significantly based on prior approach. A GTR was achieved in 14 (63\%) of 22 patients with prior transsphenoidal microscopic approach, and 10 (53\%) of 19 with prior endonasal endoscopic approach.

Of the patients with Knosp-Steiner Grade 1 or 2 invasion, $5(83.3 \%$ ) of 6 achieved a GTR (Fig. 2A and B). Of the patients with Knosp-Steiner Grade 3 or 4, 4 (36.4\%) of 11 achieved a GTR $(\mathrm{p}=0.02)$. Of those with suprasellar tumor, complete resection of the suprasellar component was achieved in 17 (94.4\%) of 18 patients (Figs. 2A and $\mathrm{B}$ and 3B). Knosp-Steiner Grade 3-4 status was significantly associated with a non-GTR $(\mathrm{p}<0.0005)$ (Fig. 3A).

The standard transsphenoidal transsellar approach was used in 14 cases; the extended transplanum $(n=12)$, transclival $(n=1)$, transcavernous $(n=7)$, combined transplanum-transcavernous $(\mathrm{n}=5)$ and transplanum-transclival $(\mathrm{n}=2)$, in poorly pneumatized sphenoid sinus, approaches were used in 27 cases. Further bony opening and use of extended approaches were more significantly required to comfortably remove tumors in patients in whom residual tumors were present postoperatively $(n=23 / 30)($ Fig. 4$)$ than those in whom tumor recurred after GTR $(n=2 / 6)(p$ $<0.05)$ (Fig. 5).

Intraoperative CSF leaks occurred in $25(61 \%)$ of 41 surgeries. The mean tumor volume was higher in cases involving intraoperative CSF leaks than in those not involving intraoperative leaks $\left(10 \mathrm{~cm}^{3}\right.$ vs $2.27 \mathrm{~cm}^{3} ; \mathrm{p}=0.008$, Mann-Whitney U-test). In the 25 patients with an intraoperative CSF leak, a nasoseptal flap was used in 12 (48\%) cases. A postoperative CSF leak occurred in only one case (2.4\%), which ceased with lumbar drainage.

Of the 17 patients with visual field impairment preoperatively, status improved in 9 patients (53\%) and was stable in $8(47 \%)$. One patient had a postoperative hematoma with transient worsening in vision, which improved following hematoma evacuation. Endocrinological remission was achieved in 14 cases (77.8\%) of 18 cases, 12 with surgery alone (hyperprolactinemia [ $=3$ ], GH-secreting $[\mathrm{n}=6]$, and ACTH-secreting $[\mathrm{n}=3]$ tumors) and an additional 2 with adjuvant medical $(n=1)$ and radiation $(n=$ 1) therapy. New endocrine deficits occurred in 6 patients (14.6\%), 2 with DI and 4 with anterior pituitary insufficiency (ACTH $[n=2])$, TSH $(n=1)$, and GH $(n=1)$.

\section{Discussion}

In this study we show that endonasal endoscopic surgery can lead to excellent results for recurrent or residual pituitary adenomas, regardless of whether the prior approach was transsphenoidal microscopic or endonasal endoscopic. In the majority of cases, postoperative residual tumor was found after the first surgery, rather than having recurred after a prior adequate resection. The presence of postoperative residual tumor did not appear to vary based on prior approach. Although we initially hypothesized that prior endoscopic surgery would be less likely to lead to residual tumor, our results show that the use of an endoscope, in and of itself, may not lead to fewer postoperative residual tumors. These results indicate that the surgeon's judgment and experience and the use of extended approaches may have more to do with the EOR than the use of an endoscope versus a microscope. Our surgical philosophy of aggressive wide bone opening and the use of extended approaches with opening of the cavernous sinus and planum, where indicated, resulted in a marked in-

TABLE 4. Proliferation index of pituitary adenomas

\begin{tabular}{lrcrc}
\hline & \multicolumn{3}{c}{ Ki 67 Expression } & \\
\cline { 2 - 4 } Characteristic & $<3 \%$ & $3 \%-5 \%$ & $>5 \%$ & p Value \\
\hline Mean vol $\left(\mathrm{cm}^{3}\right)$ & 4 & 3.65 & 22 & 0.008 \\
\hline Invasion & 11 & 5 & 6 & $<0.05$ \\
\hline Recurrence \& reop & 2 & - & $4 / 6$ & 0.0065 \\
\hline EOR & $95 \%$ & $96 \%$ & $79 \%$ & 0.053 \\
\hline GTR & $11 / 17$ & $5 / 7$ & $1 / 6$ & 0.083 \\
\hline
\end{tabular}



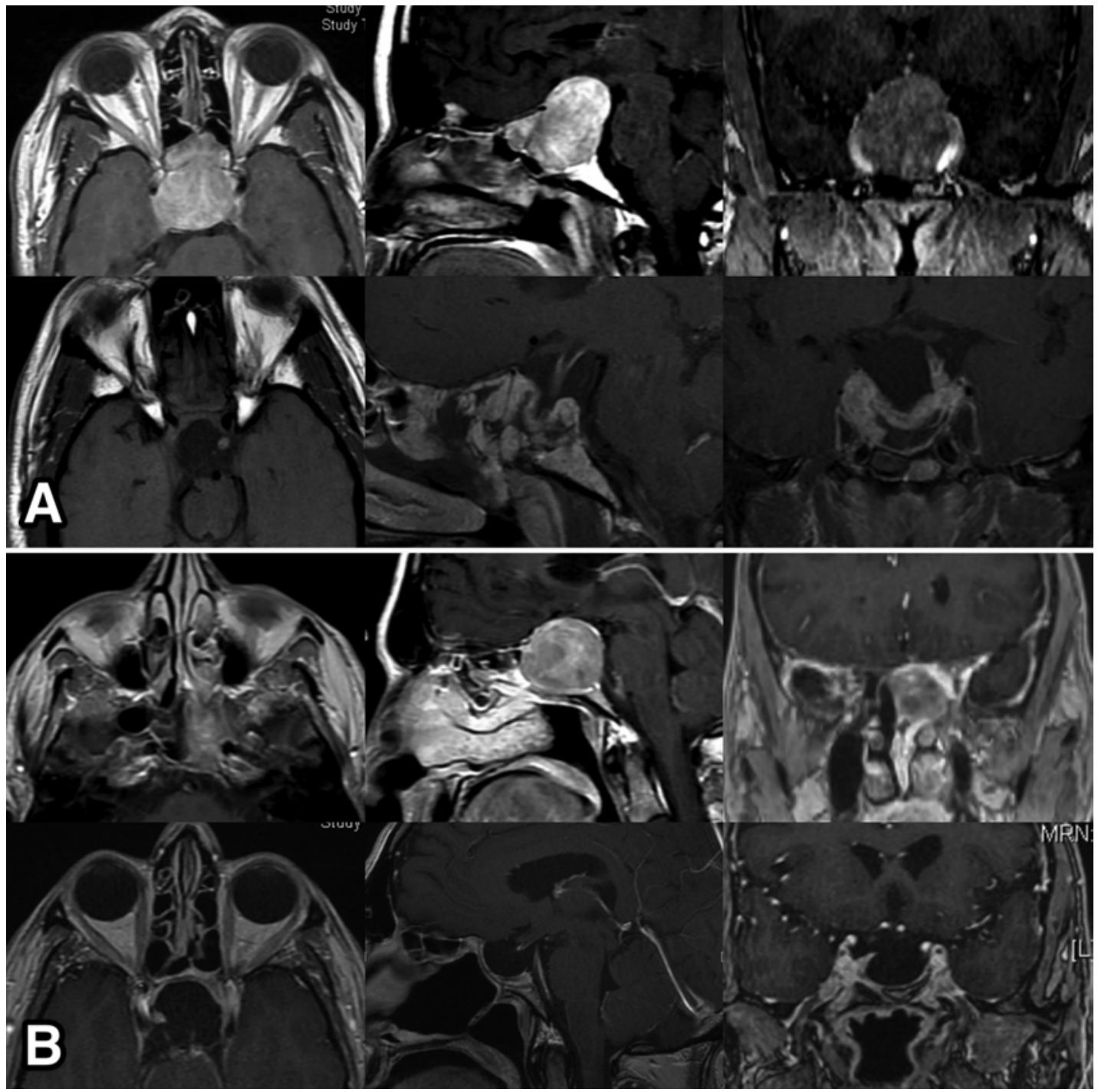

FIG. 2. Regrowth after prior microscopic transsphenoidal approach shown on preoperative (upper) and postoperative (lower) images. A: Regrowth of a giant pituitary adenoma filling the sphenoid sinus and with suprasellar extension. GTR was achieved through extended endoscopic endonasal approach. B: Characteristic pattern of tumor regrowth filling half of the sphenoid sinus. A speculum-based microscopic approach failed to fully expose the sellar tumor on the left of a sphenoid septation, which further continued to grow. An endoscopic endonasal approach was used to have wide corridor and fully expose the tumor, and GTR was achieved.

crease in EOR compared with prior approaches. Only the lateral compartment of the cavernous sinus was a barrier to complete tumor removal, which follows with our general surgical philosophy to explore the medial cavernous sinus to remove soft tumor without risking permanent damage to the cranial nerves. ${ }^{16,67}$ Tumor in the lateral cavernous sinus that cannot be reached through a medial approach can be more safely addressed with stereotactic radiosurgery, particularly in non-hormone-producing tumors for which a complete resection is less critical. More aggressive attempts at resecting tumor in the lateral compartment are associated with higher rate of morbidity. ${ }^{19,67}$

We have also found that residual tumor after prior endoscopic endonasal surgery is more common in sellar locations, whereas residual is more common in parasellar areas after transsphenoidal microscopic surgery. The increased rate of residual tumor in the sphenoid sinus after microscopic surgery has been a consistent finding. The most common cause is failure to adequately open all the sphenoid septations and to adequately open the face of the sphenoid sinus. Inherent in the endonasal endoscopic approach is a wider sphenoidotomy since the endoscope itself must be placed in the sinus, and, hence, there is a requirement to make room for the scope. This aspect of the approach and technique may lead to more complete exposure of the sphenoid and thus more complete resection of tumor from the sphenoid. Moreover, the panoramic view provided by the endoscope may impact tumor removal in the sinus compared with the more limited view provided by the microscope, whose lens and light source are outside the head and whose field of view is restricted by the narrow corridor. Such a limitation in the field of view may 

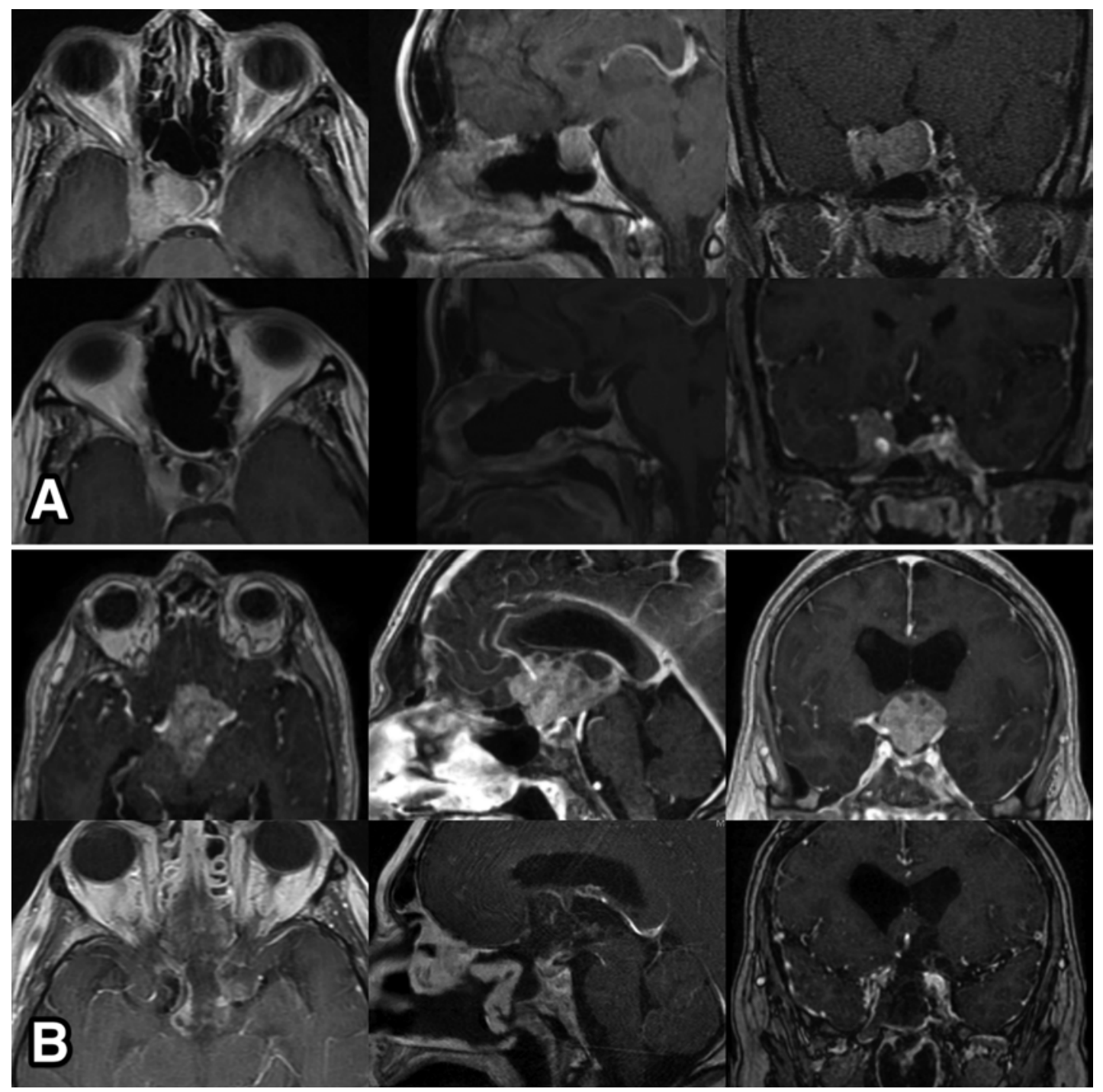

FIG. 3. Regrowth after prior endoscopic transsphenoidal approach shown on preoperative (upper) and postoperative (lower) images. A: Regrowth of small tumor residue in the cavernous sinus. Using an extended endonasal endoscopic approach, the tumor was removed from the sella and medial part of cavernous sinus; adjunctive stereotactic radiosurgery was then recommended. B: Regrowth of a giant adenoma with suprasellar extension with deteriorating vision. Near-total resection was achieved with an extended endonasal endoscopic approach, and the patient's vision was stabilized.

also lead to increased residual in the suprasellar cistern after prior microscopic compared with endoscopic approaches. This finding has been noted previously by Tajudeen et al., who reported that in $12(44.5 \%)$ of 27 patients with residual tumor after prior speculum-based microscopic transsphenoidal surgery, the residual tumors were located in the suprasellar region and cavernous sinus. ${ }^{64}$ McLaughlin et al. and Dhandapani et al. also emphasized the benefit of the endonasal endoscopic approach for removing additional tumor from both suprasellar region and cavernous sinus, respectively, that could not be retrieved by the microscopic approach. ${ }^{16,46}$

Perhaps the more surprising finding is the frequency of residual tumor in the sella after prior endonasal endoscopic surgery. Although one might suppose that this represents a higher percentage of inadequately resected small hormone-producing tumors, the rate of such tumors was the same as that of the microscopic transsphenoidal group. One possible explanation is that the endoscopic endonasal approach is less effective at removing tumor within the sella, but an anatomical or technical explanation for this finding is not immediately apparent.

\section{Extent of Resection}

The literature on endoscopic endonasal reoperation demonstrates that GTR rates range from $40 \%$ to $63 \%$ (Table 5). These rates are slightly lower than first-time operations for which GTR rates average $78 \% .^{62}$ Although there are few reports on reoperation using the microscopic speculum-based transsphenoidal approach, GTR rates appear to be similar, ranging from $55 \%$ to $58.5 \%$. $^{2,6,10,29,43,62,64,66,68}$ The fact that the endoscope does not appear to markedly improve rates of GTR is surprising. Although it is possible that the endoscope offers no advantage in this situation, 

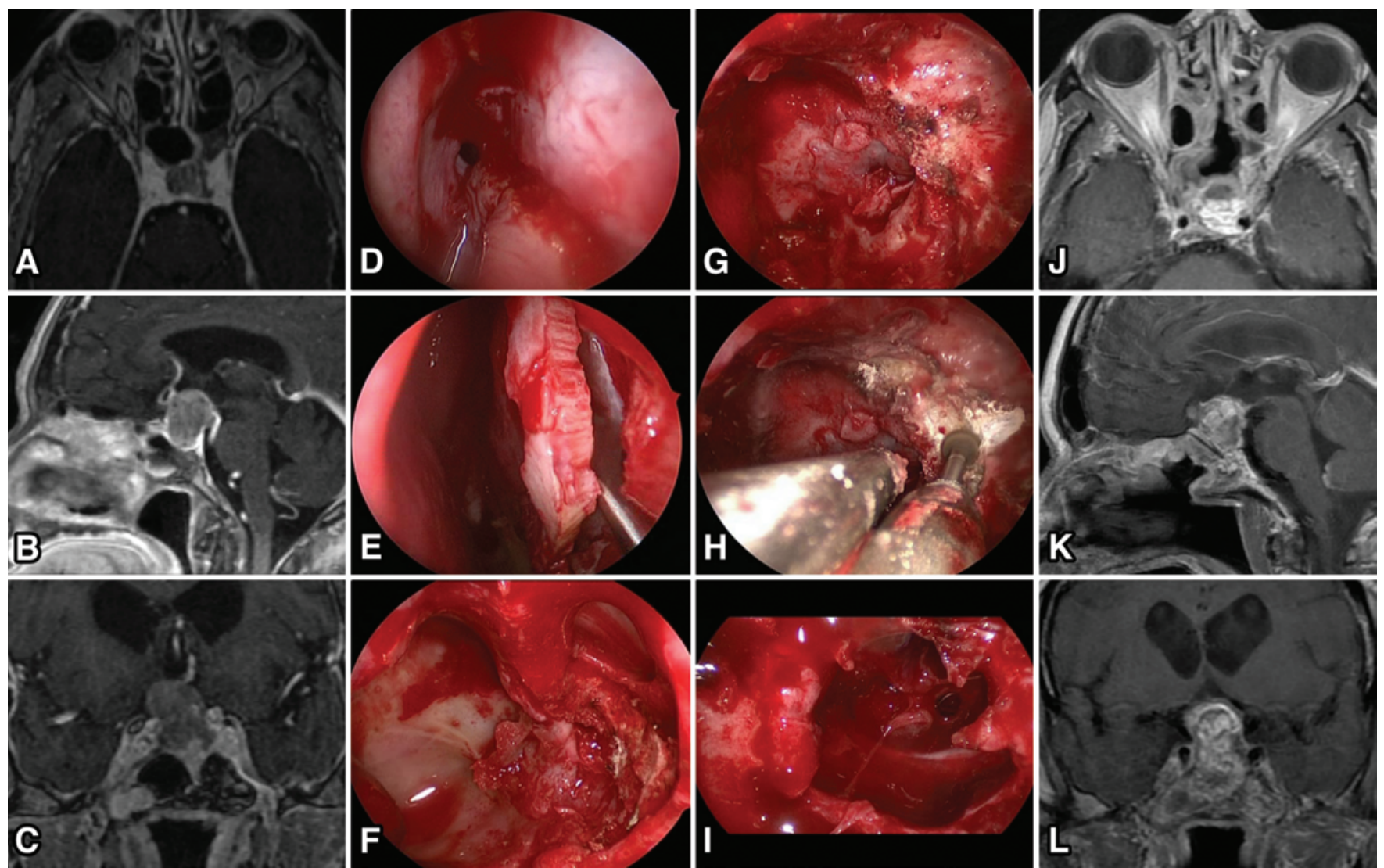

FIG. 4. Growth of a residual nonfunctioning pituitary adenoma in a patient who presented with diminution of vision after prior endoscopic endonasal surgery, which failed to remove the adenoma. A-C: Early postoperative follow-up MR images revealed nearly the same tumor mass as preoperatively; the nasal septum was preserved with a small opening of the sphenoid sinus (A and B). D-I: Images depicting the endoscopic endonasal reoperation. Identification and widening of the sphenoid ostium and elevation of the nasal septal flap (D); resection of the posterior part of the nasal septum (E); removal of bony sphenoidal septum that led to bilateral opening of the sphenoid sinus $(F)$. Mucosa of the sphenoid sinus was dissected from the walls of the sphenoid, adhesions to the sellar dura were cut, and exploration of bony sellar floor revealed a small bony opening that was inadequate for full tumor exposure $(G)$. Widening the bony opening enabled exposure of the tumor, and GTR was then performed (H and I). J-L: Postoperative MR images showing resected nasal septum, bilaterally widely opened sphenoid sinus, and GTR of the tumor. Figure is available in color online only.

other explanations include case selection bias and differing methods of determining GTR. Another possibility is that the value of a reoperation is that the intervening imaging shows the location of the residual tumor that was missed in the first operation. This knowledge is essential for locating the residual tumor to be treated in the second operation, regardless of whether a microscope or an endoscope is used. Another possibility is that cases selected for reoperation using the sublabial microscopic approach are those that can be reached with this approach. There may be a wider array of tumors in different locations that can now be treated by endoscope-assisted reoperation via extended approaches, but the overall rates of GTR are similar. Supporting this explanation are the studies showing that after microscopic transsphenoidal surgery, additional tumor can be found and removed with the endoscope that was not initially visualized with the microscope ${ }^{46}$ Similarly other studies from different centers have emphasized the value of the endoscopic endonasal approach in reoperation of recurrent or regrown pituitary adenomas after prior microscopic transsphenoidal surgery., ${ }^{2,10,29,64}$ Regardless of the explanation, lateral cavernous sinus invasion remains the greatest limiting factor. ${ }^{10,16,58}$

However, using GTR as an end point is perhaps misleading in pituitary adenomas and not the best end point. Since these are benign, slow-growing tumors that create symptoms based on mass effect and hormone overproduction, EOR and hormone and symptom resolution are more important. In our series the mean EOR rate was 93.7\%, and visual improvement and hormone resolution rates were $53 \%$ and $77.8 \%$, respectively, with no visual deterioration. In an earlier report of our operations for macroadenomas, the EOR was $97.8 \%$ and visual improvement and hormone resolution were $80.8 \%$ and $45 \% .{ }^{26}$ In a series of purely functional tumors of all sizes, hormone resolution was $60 \%{ }^{27}$ These results are fairly comparable to our reoperation results.

\section{Complications}

Reoperations, in general, carry a higher complication rate than first-time operations for all surgical interventions based on the body's natural ability to heal by scar forma- 


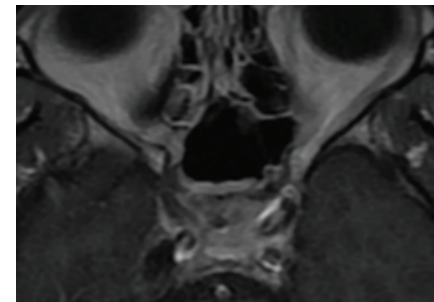

A
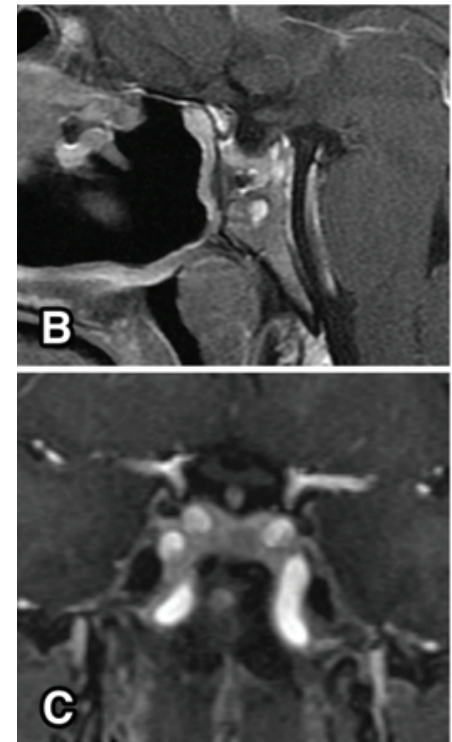
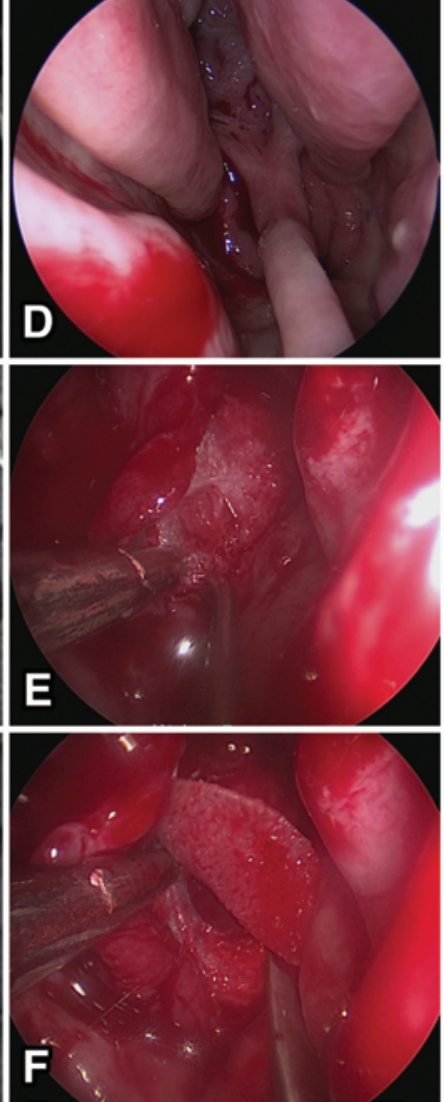
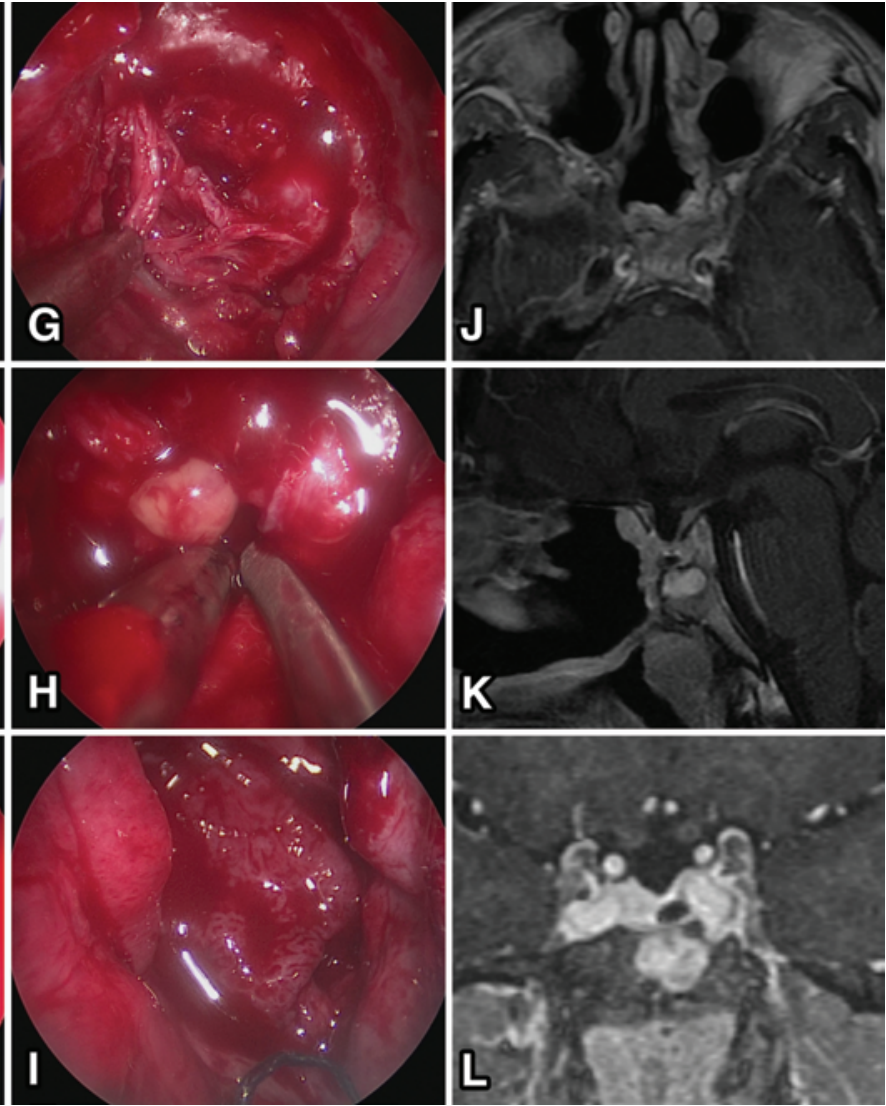
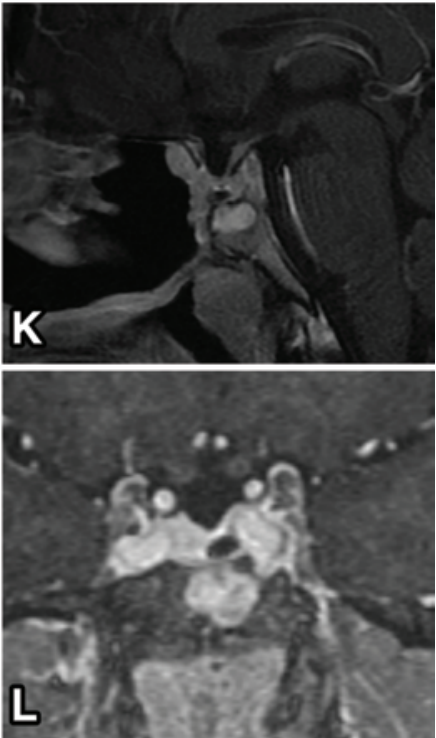

FIG. 5. Recurrent GH-secreting adenoma after prior endoscopic endonasal GTR. A-C: Preoperative MR images showing posterior nasal septum resection and wide sphenoidotomy. D-I: Endoscopic endonasal approach. D: Resected nasal septum and nasal septal flap on the posterior nasal wall. E: We dissected the nasal flap of the reconstructed opening. F: Removal of the Medpor implant. G: The wide opening of the sellar floor was noted, and no significant further bony opening was necessary to expose the tumor. H: The tumor was resected. I: We replaced the preserved nasal flap to reconstruct the sellar floor. J-L: Postoperative MR images showing the resected nasal septum, bilaterally widely opened sphenoid sinus, and GTR of the tumor. Figure is available in color online only.

tion. With respect to postoperative CSF leak, our data show that reoperations do not appear to carry a higher rate of postoperative CSF leak than first-time operations. Our rates of intraoperative CSF leak were high, likely because of breaches in the arachnoid and scarring that occurred as a result of the first operation. The development of multilayer closure techniques and the use of vascularized flaps have reduced rates of postoperative CSF leaks across the board and clearly impact the rates of leak for reoperative pituitary surgery as well. ${ }^{31,42,54}$ Nasoseptal flaps could be harvested or reused in the majority of cases.

New cases of anterior and posterior pituitary insufficiency were only slightly more common following reoperative surgery. ${ }^{23,30,51}$ In a meta-analysis of endoscopic pituitary surgeries, transient DI was reported in 7\%, permanent DI in $2.5 \%$, and anterior pituitary insufficiency in $1.5 \%$ of cases treated with endoscopic pituitary surgery. ${ }^{62}$ For our macroadenoma series, the combined rate of anterior and posterior pituitary insufficiency was almost $10 \% .{ }^{26}$ However, since many of the patients undergoing reoperation had preexisting endocrinopathy from their prior surgery, the comparison is not a fair one. Rates of complications following reoperative pituitary surgery in the literature range from $9.4 \%$ to $31.3 \%{ }^{2,6,10,29,43,58,64,66,68}$ (Table 5). In a recent population-based study, Krings et al. reported a similar complication rate for first-time and reoperative transsphenoidal surgery. ${ }^{35}$ However, in this study rates of complications were higher for reoperation in many subcategories, but the numbers were not high enough to achieve significance. Also, the authors were not allowed to publish the numbers in their paper, so the data cannot be adequately analyzed.

\section{Limitations}

Several limitations to our study exist. First, this is a retrospective study so most data were acquired by chart review. However this is a consecutive series of cases, and the database was created prospectively, so no cases were missing. Also, these cases represent only those recurrences that were brought to surgery. We cannot make any conclusions regarding recurrences in patients who were treated in any other way. Hence, the overall percentage of cases requiring reoperation cannot be determined. Finally, tumor volumes were determined using an ellipsoid approximation rather than volumetrics. In a prior study we have shown that using an ellipsoid model overestimates the volume of 
TABLE 5. Literature review of prior reports of reoperation for recurrent pituitary tumors based on operative approach

\begin{tabular}{|c|c|c|c|c|c|c|c|c|c|c|}
\hline \multirow[b]{2}{*}{ Authors \& Year } & \multirow{2}{*}{$\begin{array}{l}\text { No. of } \\
\text { Cases }\end{array}$} & \multicolumn{4}{|c|}{ EOR (no. of cases, \%) } & \multicolumn{4}{|c|}{ No. of Cases, $\%$ of Cases } & \multirow[b]{2}{*}{ Other Complications } \\
\hline & & GTR & NTR & STR & PR & Complications & Hypopit & DI & CSF leak & \\
\hline \multicolumn{11}{|c|}{ Endoscopic reoperation } \\
\hline Current study & 41 & $24,55.5 \%$ & $14,34.1 \%$ & $2,4.9 \%$ & $1,2.4 \%$ & $8,19.5 \%$ & $4,9.7 \%$ & $2,4.9 \%$ & $1,2.4 \%$ & Hematoma: 1 (2.4\%) \\
\hline $\begin{array}{l}\text { Tajudeen et al., } \\
2015\end{array}$ & 27 & $17,63 \%$ & $3,11 \%$ & $7,26 \%$ & 0 & $6,22 \%$ & $1,3.7 \%$ & $2,7.4 \%$ & 0 & $\begin{array}{l}\text { Abducent palsy: } 1(3.7 \%) \text {, } \\
\text { Hypotension \& ICU } \\
\quad \text { admission: } 2(7.4 \%)\end{array}$ \\
\hline $\begin{array}{l}\text { Hwang et al., } \\
2013\end{array}$ & 30 & $15,50 \%$ & $2,7 \%$ & $7,23 \%$ & $6,20 \%$ & $5,16 \%$ & $1,3.3 \%^{*}$ & $\begin{array}{c}4(13.3 \%) \\
\text { temp }\end{array}$ & 0 & $\begin{array}{l}\text { Meningitis: } 2 \text { (6.7\%), PE: } \\
\quad 1(3.3 \%)\end{array}$ \\
\hline $\begin{array}{l}\text { Cavallo et al., } \\
2012\end{array}$ & 59 & $37,63 \%$ & $8,13.5 \%$ & $9,15 \%$ & $5,8.5 \%$ & $8,13.5 \%$ & $4,6.7 \%$ & $\begin{array}{c}3(5 \%) \\
\text { temp }\end{array}$ & $1(1.7 \%) \dagger$ & $\begin{array}{l}\text { Hematoma: } 1(1.7 \%) \\
\text { 6th nerve palsy: } 2(3.4 \%)\end{array}$ \\
\hline $\begin{array}{l}\text { Alahmadi et } \\
\text { al., } 2011\end{array}$ & 39 & $18,46 \%$ & 0 & $21,54 \%$ & 0 & $6,13 \%$ & 0 & 0 & $1(2.6 \%) \dagger$ & $\begin{array}{l}1 \mathrm{Ml}, 1 \mathrm{HCP}, 1 \text { sinusitis, } 1 \\
\text { crusting }\end{array}$ \\
\hline $\begin{array}{l}\text { Rudnik et al., } \\
\qquad 2006\end{array}$ & 20 & $8,40 \%$ & & & & $4,20 \%$ & $3,15 \%$ & & $1,5 \%$ & \\
\hline \multicolumn{11}{|c|}{ Microscopic reoperation } \\
\hline $\begin{array}{l}\text { Wang et al., } \\
2015\end{array}$ & 29 & $16,55 \%$ & & $11,38 \%$ & $2,7 \%$ & $5,17 \%$ & & $1,3.4 \%$ & $1,3.4 \%$ & $\begin{array}{l}2(6.9 \%) \text { cases of deterio- } \\
\text { ration of vision due to } \\
\text { hemorrhage in tumor } \\
\text { bed \& intracranially; } \\
\text { 6th nerve palsy: } 1(3.4 \%)\end{array}$ \\
\hline $\begin{array}{l}\text { Yamada et al., } \\
2010\end{array}$ & 53 & $31,58.5 \%$ & & & & $5,9 \%$ & $1,2 \%$ & $1,2 \%$ & $1,2 \%$ & $\begin{array}{l}\text { Epistaxis: } 1(2 \%) \text {, pituitary } \\
\text { abscess: } 1(2 \%)\end{array}$ \\
\hline $\begin{array}{l}\text { Mattozo et al., } \\
2006\end{array}$ & 30 & $17,57 \%$ & & & & $5,17 \%$ & $\begin{array}{l}\text { Hypoth: } 1 \text {, } \\
3.3 \%\end{array}$ & $1,3.3 \%$ & $1,3.3 \%$ & $\begin{array}{l}\text { Sinusitis: } 1(3.3 \%), \text { hypo- } \\
\text { natremia: } 1(3.3 \%)\end{array}$ \\
\hline $\begin{array}{l}\text { Benveniste et } \\
\text { al., } 2005\end{array}$ & 96 & & & & & $29,30 \%$ & $15,15.6 \%$ & $5,5.2 \%$ & $1,1 \%$ & $\begin{array}{l}\text { CN palsy: } 1 \text {, graft site } \\
\text { infection: } 1 \text {, sinusitis: } 5 \text {, } \\
\text { epistaxis: } 1\end{array}$ \\
\hline
\end{tabular}

$\mathrm{CN}=$ cranial nerve; $\mathrm{HCP}=$ hydrocephalus; Hypopit = hypopituitarism; Hypoth = hypothyroidism; $\mathrm{Ml}$ = myocardial infarction; $\mathrm{NTR}=$ near-total resection; $\mathrm{PE}=$ pulmonary embolism; PR = partial resection; temp = temporary.

* Represents a case of hypocortisolemia.

$\dagger$ Patient also had meningitis.

the tumor by roughly $16 \% .{ }^{12}$ This error is worse for tumors $>40 \mathrm{~cm}^{3}$, of which there was only one case in this study. However, our prior study shows that the ellipsoid model, while not perfect, provides a good approximation of the volume of the tumor.

\section{Conclusions}

Endonasal endoscopic reoperation offers excellent results for residual or recurrent tumors and should be considered before radiation therapy, particularly for symptomatic patients. The majority of cases are performed for residual tumors after inadequate first operations. Rates of resection, hormonal cure, and complications are slightly less favorable but overall comparable to first-time operations. The locations of recurrent or residual tumor were more likely parasellar and sphenoidal following prior microscopic transsphenoidal surgery and sellar following prior endonasal endoscopic surgery.

\section{References}

1. Abosch A, Tyrrell JB, Lamborn KR, Hannegan LT, Applebury CB, Wilson CB: Transsphenoidal microsurgery for growth hormone-secreting pituitary adenomas: initial outcome and long-term results. J Clin Endocrinol Metab 83:3411-3418, 1998

2. Alahmadi H, Dehdashti AR, Gentili F: Endoscopic endonasal surgery in recurrent and residual pituitary adenomas after microscopic resection. World Neurosurg 77:540-547, 2012

3. Arnaldi G, Angeli A, Atkinson AB, Bertagna X, Cavagnini F, Chrousos GP, et al: Diagnosis and complications of Cushing's syndrome: a consensus statement. J Clin Endocrinol Metab 88:5593-5602, 2003

4. Banu MA, Kim JH, Shin BJ, Woodworth GF, Anand VK, Schwartz TH: Low-dose intrathecal fluorescein and etiologybased graft choice in endoscopic endonasal closure of CSF leaks. Clin Neurol Neurosurg 116:28-34, 2014

5. Barkan AL: Acromegaly. Trends Endocrinol Metab 3:205210, 1992

6. Benveniste RJ, King WA, Walsh J, Lee JS, Delman BN, Post KD: Repeated transsphenoidal surgery to treat recurrent or residual pituitary adenoma. J Neurosurg 102:1004-1012, 2005

7. Cappabianca P, Alfieri A, Colao A, Cavallo LM, Fusco M, Peca C, et al: Endoscopic endonasal transsphenoidal surgery in recurrent and residual pituitary adenomas: technical note. Minim Invasive Neurosurg 43:38-43, 2000

8. Cappabianca P, Solari D: The endoscopic endonasal approach for the treatment of recurrent or residual pituitary adenomas: widening what to see expands what to do? World Neurosurg 77:455-456, 2012 
9. Casanueva FF, Molitch ME, Schlechte JA, Abs R, Bonert V, Bronstein MD, et al: Guidelines of the Pituitary Society for the diagnosis and management of prolactinomas. Clin Endocrinol (Oxf) 65:265-273, 2006

10. Cavallo LM, Solari D, Tasiou A, Esposito F, de Angelis M, D'Enza AI, et al: Endoscopic endonasal transsphenoidal removal of recurrent and regrowing pituitary adenomas: experience on a 59-patient series. World Neurosurg 80:342-350, 2013

11. Chanson P, Salenave S: Diagnosis and treatment of pituitary adenomas. Minerva Endocrinol 29:241-275, 2004

12. Chohan MO, Levin AM, Singh R, Zhou Z, Green CL, Kazam $\mathrm{JJ}$, et al: Three-dimensional volumetric measurements in defining endoscope-guided giant adenoma surgery outcomes. Pituitary 19:311-321, 2016

13. Ciccarelli E, Ghigo E, Miola C, Gandini G, Muller EE, Camanni F: Long-term follow-up of 'cured' prolactinoma patients after successful adenomectomy. Clin Endocrinol (Oxf) 32:583-592, 1990

14. Dehdashti AR, Ganna A, Karabatsou K, Gentili F: Pure endoscopic endonasal approach for pituitary adenomas: early surgical results in 200 patients and comparison with previous microsurgical series. Neurosurgery 62:1006-1017, 2008

15. Dhandapani S, Negm HM, Cohen S, Anand VK, Schwartz TH: Endonasal endoscopic transsphenoidal resection of tuberculum sella meningioma with anterior cerebral artery encasement. Cureus 7:e311, 2015

16. Dhandapani S, Singh H, Negm HM, Cohen S, Anand VK, Schwartz TH: Cavernous sinus invasion in pituitary adenomas: systematic review and pooled data meta-analysis of radiological criteria and comparison of endoscopic and microscopic surgery. World Neurosurg [epub ahead of print], 2016

17. Dhandapani S, Singh H, Negm HM, Cohen S, Souweidane MM, Greenfield JP, et al: Endonasal endoscopic reoperation for residual or recurrent craniopharyngiomas. J Neurosurg [epub ahead of print May 6, 2016. DOI: 10.3171/2016.1.JNS152238]

18. Ezzat S, Asa SL, Couldwell WT, Barr CE, Dodge WE, Vance ML, et al: The prevalence of pituitary adenomas: a systematic review. Cancer 101:613-619, 2004

19. Ferreli F, Turri-Zanoni M, Canevari FR, Battaglia P, Bignami M, Castelnuovo P, et al: Endoscopic endonasal management of non-functioning pituitary adenomas with cavernous sinus invasion: a 10- year experience. Rhinology 53:308-316, 2015

20. Fraser JF, Mass AY, Brown S, Anand VK, Schwartz TH: Transnasal endoscopic resection of a cavernous sinus hemangioma: technical note and review of the literature. Skull Base 18:309-315, 2008

21. Giustina A, Chanson P, Bronstein MD, Klibanski A, Lamberts S, Casanueva FF, et al: A consensus on criteria for cure of acromegaly. J Clin Endocrinol Metab 95:3141-3148, 2010

22. Golden SH, Robinson KA, Saldanha I, Anton B, Ladenson PW: Clinical review: Prevalence and incidence of endocrine and metabolic disorders in the United States: a comprehensive review. J Clin Endocrinol Metab 94:1853-1878, 2009

23. Halvorsen H, Ramm-Pettersen J, Josefsen R, Rønning P, Reinlie S, Meling T, et al: Surgical complications after transsphenoidal microscopic and endoscopic surgery for pituitary adenoma: a consecutive series of 506 procedures. Acta Neurochir (Wien) 156:441-449, 2014

24. Hofstetter C, Anand VK, Schwartz TH: Endoscopic transsphenoidal pituitary surgery. Oper Tech Otolaryngol 22:206-214, 2011

25. Hofstetter CP, Mannaa RH, Mubita L, Anand VK, Kennedy JW, Dehdashti AR, et al: Endoscopic endonasal transsphenoidal surgery for growth hormone-secreting pituitary adenomas. Neurosurg Focus 29(4):E6, 2010

26. Hofstetter CP, Nanaszko MJ, Mubita LL, Tsiouris J, Anand
VK, Schwartz TH: Volumetric classification of pituitary macroadenomas predicts outcome and morbidity following endoscopic endonasal transsphenoidal surgery. Pituitary 15:450-463, 2012

27. Hofstetter CP, Shin BJ, Mubita L, Huang C, Anand VK, Boockvar JA, et al: Endoscopic endonasal transsphenoidal surgery for functional pituitary adenomas. Neurosurg Focus 30(4):E10, 2011

28. Hornyak M, Couldwell WT: Multimodality treatment for invasive pituitary adenomas. Postgrad Med 121:168-176, 2009

29. Hwang JM, Kim YH, Kim JW, Kim DG, Jung HW, Chung YS: Feasibility of endoscopic endonasal approach for recurrent pituitary adenomas after microscopic trans-sphenoidal approach. J Korean Neurosurg Soc 54:317-322, 2013

30. Jahangiri A, Wagner J, Han SW, Zygourakis CC, Han SJ, Tran MT, et al: Morbidity of repeat transsphenoidal surgery assessed in more than 1000 operations. J Neurosurg 121:6774,2014

31. Jakimovski D, Bonci G, Attia M, Shao H, Hofstetter C, Tsiouris AJ, et al: Incidence and significance of intraoperative cerebrospinal fluid leak in endoscopic pituitary surgery using intrathecal fluorescein. World Neurosurg 82: e513e523, 2014

32. Jho HD, Carrau RL: Endoscopic endonasal transsphenoidal surgery: experience with 50 patients. J Neurosurg 87:44-51, 1997

33. Knosp E, Steiner E, Kitz K, Matula C: Pituitary adenomas with invasion of the cavernous sinus space: a magnetic resonance imaging classification compared with surgical findings. Neurosurgery 33:610-618, 1993

34. Komotar RJ, Starke RM, Raper DMS, Anand VK, Schwartz TH: Endoscopic skull base surgery: a comprehensive comparison with open transcranial approaches. Br J Neurosurg 26:637-648, 2012

35. Krings JG, Kallogjeri D, Wineland A, Nepple KG, Piccirillo JF, Getz AE: Complications following primary and revision transsphenoidal surgeries for pituitary tumors. Laryngoscope 125:311-317, 2015

36. Lake MG, Krook LS, Cruz SV: Pituitary adenomas: an overview. Am Fam Physician 88:319-327, 2013

37. Laufer I, Anand VK, Schwartz TH: Endoscopic, endonasal extended transsphenoidal, transplanum transtuberculum approach for resection of suprasellar lesions. J Neurosurg 106:400-406, 2007

38. Laws ER Jr, Thapar K: Surgical management of pituitary adenomas. Baillieres Clin Endocrinol Metab 9:391-405, 1995

39. Levy A: Pituitary disease: presentation, diagnosis, and management. J Neurol Neurosurg Psychiatry 75 (Suppl 3):iii47-iii52, 2004

40. Liu JK, Couldwell WT: Contemporary management of prolactinomas. Neurosurg Focus 16(4):E2, 2004

41. Long H, Beauregard H, Somma M, Comtois R, Serri O, Hardy J: Surgical outcome after repeated transsphenoidal surgery in acromegaly. J Neurosurg 85:239-247, 1996

42. Mascarenhas L, Moshel YA, Bayad F, Szentirmai O, Salek AA, Leng LZ, et al: The transplanum transtuberculum approaches for suprasellar and sellar-suprasellar lesions: avoidance of cerebrospinal fluid leak and lessons learned. World Neurosurg 82:186-195, 2014

43. Mattozo CA, Dusick JR, Esposito F, Mora H, Cohan P, Malkasian D, et al: Suboptimal sphenoid and sellar exposure: a consistent finding in patients treated with repeat transsphenoidal surgery for residual endocrine-inactive macroadenomas. Neurosurgery 58:857-865, 2006

44. McCoul ED, Anand VK, Schwartz TH: Endoscopic approaches to the cavernous sinus. Oper Tech Otolaryngol 22:263-268, 2011 
45. McCoul ED, Bedrosian JC, Akselrod O, Anand VK, Schwartz TH: Preservation of multidimensional quality of life after endoscopic pituitary adenoma resection. J Neurosurg 123:813-820, 2015

46. McLaughlin N, Eisenberg AA, Cohan P, Chaloner CB, Kelly DF: Value of endoscopy for maximizing tumor removal in endonasal transsphenoidal pituitary adenoma surgery. J Neurosurg 118:613-620, 2013

47. Mehta GU, Jane JA Jr: Pituitary tumors. Curr Opin Neurol 25:751-755, 2012

48. Moraes AB, Silva CM dos S, Vieira Neto L, Gadelha MR: Giant prolactinomas: the therapeutic approach. Clin Endocrinol (Oxf) 79:447-456, 2013

49. Nemergut EC, Zuo Z, Jane JA Jr, Laws ER Jr: Predictors of diabetes insipidus after transsphenoidal surgery: a review of 881 patients. J Neurosurg 103:448-454, 2005

50. Nieman LK, Biller BMK, Findling JW, Newell-Price J, Savage MO, Stewart PM, et al: The diagnosis of Cushing's syndrome: an Endocrine Society Clinical Practice Guideline. J Clin Endocrinol Metab 93:1526-1540, 2008

51. Nishioka H, Haraoka J, Ikeda Y: Risk factors of cerebrospinal fluid rhinorrhea following transsphenoidal surgery. Acta Neurochir (Wien) 147:1163-1166, 2005

52. Oh MC, Kunwar S, Blevins L, Aghi MK: Medical versus surgical management of prolactinomas. Neurosurg Clin $\mathbf{N}$ Am 23:669-678, 2012

53. Olson BR, Gumowski J, Rubino D, Oldfield EH: Pathophysiology of hyponatremia after transsphenoidal pituitary surgery. J Neurosurg 87:499-507, 1997

54. Patel KS, Komotar RJ, Szentirmai O, Moussazadeh N, Raper DM, Starke RM, et al: Case-specific protocol to reduce cerebrospinal fluid leakage after endonasal endoscopic surgery. J Neurosurg 119:661-668, 2013

55. Placantonakis DG, Tabaee A, Anand VK, Hiltzik D, Schwartz TH: Safety of low-dose intrathecal fluorescein in endoscopic cranial base surgery. Neurosurgery 61 (3 Suppl):161-166, 2007

56. Raithatha R, McCoul ED, Woodworth GF, Schwartz TH, Anand VK: Endoscopic endonasal approaches to the cavernous sinus. Int Forum Allergy Rhinol 2:9-15, 2012

57. Raza SM, Banu MA, Donaldson A, Patel KS, Anand VK, Schwartz TH: Sensitivity and specificity of intrathecal fluorescein and white light excitation for detecting intraoperative cerebrospinal fluid leak in endoscopic skull base surgery: a prospective study. J Neurosurg 124:621-626, 2016

58. Rudnik A, Zawadzki T, Gałuszka-Ignasiak B, Bazowski P, Duda I, Wojtacha M, et al: Endoscopic transsphenoidal treatment in recurrent and residual pituitary adenomas-first experience. Minim Invasive Neurosurg 49:10-14, 2006

59. Schwartz TH, Anand VK: The endoscopic endonasal transsphenoidal approach to the suprasellar cistern. Clin Neurosurg 54:226-235, 2007
60. Seckl J, Dunger D: Postoperative diabetes insipidus. BMJ 298:2-3, 1989

61. Sheehan JM, Sheehan JP, Douds GL, Page RB: DDAVP use in patients undergoing transsphenoidal surgery for pituitary adenomas. Acta Neurochir (Wien) 148:287-291, 2006

62. Tabaee A, Anand VK, Barrón Y, Hiltzik DH, Brown SM, Kacker A, et al: Endoscopic pituitary surgery: a systematic review and meta-analysis. J Neurosurg 111:545-554, 2009

63. Tabaee A, Placantonakis DG, Schwartz TH, Anand VK: Intrathecal fluorescein in endoscopic skull base surgery. Otolaryngol Head Neck Surg 137:316-320, 2007

64. Tajudeen BA, Mundi J, Suh JD, Bergsneider M, Wang MB: Endoscopic endonasal surgery for recurrent pituitary tumors: technical challenges to the surgical approach. J Neurol Surg B Skull Base 76:50-56, 2015

65. Vance ML: Treatment of patients with a pituitary adenoma: one clinician's experience. Neurosurg Focus 16(4):E1, 2004

66. Wang S, Xiao D, Wang R, Wei L, Hong J: Repeated transsphenoidal surgery for resection of pituitary adenoma. J Craniofac Surg 26:452-455, 2015

67. Woodworth GF, Patel KS, Shin B, Burkhardt JK, Tsiouris AJ, McCoul ED, et al: Surgical outcomes using a medial-tolateral endonasal endoscopic approach to pituitary adenomas invading the cavernous sinus. J Neurosurg 120:1086-1094, 2014

68. Yamada S, Fukuhara N, Oyama K, Takeshita A, Takeuchi Y: Repeat transsphenoidal surgery for the treatment of remaining or recurring pituitary tumors in acromegaly. Neurosurgery 67:949-956, 2010

\section{Disclosures}

Dr. Schwartz owns stock in VisionSense and has received nonstudy-related clinical or research support from Karl Storz.

\section{Author Contributions}

Conception and design: Schwartz, Negm, Anand. Acquisition of data: Negm, Pai, Singh, Cohen, Dhandapani. Analysis and interpretation of data: Negm. Drafting the article: Negm. Critically revising the article: Schwartz, Negm, Al-Mahfoudh, Anand. Reviewed submitted version of manuscript: Schwartz, Negm, Al-Mahfoudh, Pai, Cohen, Dhandapani, Anand. Approved the final version of the manuscript on behalf of all authors: Schwartz. Statistical analysis: Schwartz, Negm. Administrative/technical/ material support: Schwartz, Negm, Anand. Study supervision: Schwartz, Anand.

\section{Correspondence}

Theodore H. Schwartz, Department of Neurosurgery, Weill Cornell Medical College, NewYork-Presbyterian Hospital, 525 East 68th St., Box 99, New York, NY 10065. email: schwarh@med. cornell.edu. 